\title{
ステップ状海底地形で発生する 長周期自由波の波向と発生限界 WAVE DIRECTION AND EXISTENCE LIMITS OF HIGHER ORDER FREE LONG WAVES OVER A SUBMERGED STEP
}

\author{
大橋 正臣 1 - 佐藤 幸雄 $^{2} \cdot$ 濱中 建一郎 3 \\ Masami OHASHI, Yukio SATO and Ken-ichiro HAMANAKA \\ 1学生会員 工修 北見工業大学大学院工学研究科（テ090-8507 北海道北見市公園町165番地）
2正会員 工博 北見工業大学教授 工学部土木開発工学科（广090-8507 北海道北見市公園町165番地）
3正会員 工博 北海道東海大学教授 工学部海洋開発工学科（广005-8601 札幌市南区南沢5-1-1-1）
}

Scattering and trapping of the higher order free long waves over a submerged step are investigated. As incident waves, two wave components with slightly different frequencies and obliquely incident angles to the step are considered. The forced waves and the free long waves are obtained up to the second order of the perturbation method. Applicability of these solutions are investigated. It is found that depending on the wave and the step conditions, the free long waves of the progressive mode can not exist in the deeper region but can exist in the shallower

Key Words : Non-linearity, free long waves, forced waves, scattering and trapping

\section{1.はじめに}

港湾内に停泊している船舶が船体動摇を起こすメ カニズムは、基本的には港湾内の副振動による湾水 振動と共振によるものと考えられる。この現象を発 生させる原因は長周期自由波にあると考えられる。 また、長周期自由波の港湾内に対する入射角は、副 振動を起こす原因に大きく関係している。合田・岡 崎 (1998) はステップ状海底地形をあげ、そこに 1 成 分波が入射する際、波の非線形干渉により自由波が 発生することを示した。合田等は自由波、拘束波に は減衰定在波を省略し、接続境界で水底から水面ま での積分值について連続式と満足するように求めて いる。本研究では、ステップ状海底地形を対象とし、 厳密に減衰定在波を考慮して解析を行うこととした。 しかし、連続条件を満足させるために係数を選点法 で求めた場合、Gibbsの現象を含んだ解となり、長 周期自由波の振幅に影響を与えると考えられるため 振幅については議論しない。ステップに対して角度 を持った入射波の非線形干渉によって発生する長周 期自由波の波向についてはGibbsの現象の影響を受 けないことから、長周期自由波の波向について詳細 に検討することを目的とする。特に進行性自由波の 発生限界から、ステップ上の領域で長周期自由波が Trapする事を示す。

\section{2. 支配方程式と摂動法}

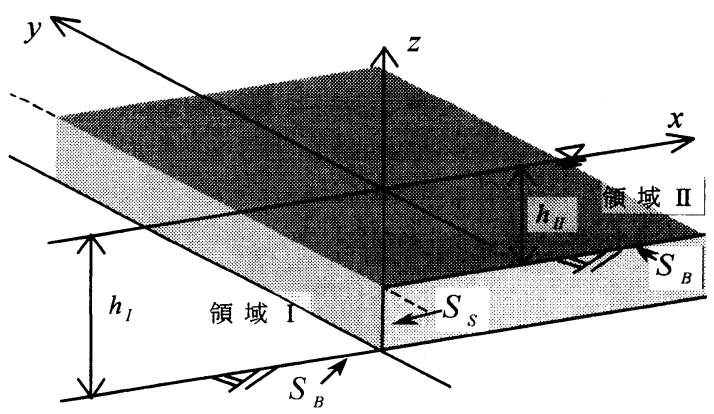

図-1 座標系

波動場はポテンシャル流とし、図-1のような座標 系を用いる。速度ポテンシャル $\Phi$ に関する基礎方程 式、境界条件は以下のようになる。

$$
\begin{gathered}
\Delta \Phi=0 \\
\Phi_{z}=\eta_{t}+\nabla \eta \cdot \nabla \Phi \text { on } z=\eta \\
\Phi_{t}+g \eta+\frac{1}{2}\left\{(\nabla \Phi)^{2}+\Phi_{z}{ }^{2}\right\}=0 \text { on } z=\eta \\
\Phi_{z}=0 \text { on } S_{B} \\
\Phi_{v}=0 \text { on } S_{S} \\
\text { ここで } \eta \text { は水面変位とし、 } \nabla \equiv(\partial / \partial x, \partial / \partial y) 、 \\
\Delta \equiv\left(\partial^{2} / \partial x^{2}+\partial^{2} / \partial y^{2}+\partial^{2} / \partial z^{2}\right) \text { とする。 }
\end{gathered}
$$


また、 $v$ はステップ全面 $S_{S}$ の 法線方向を示す。

次に非線形性の強さを表すパラメータ $\varepsilon$ で、 $\Phi$ と $\eta$ を摂動展開する。

$$
\begin{aligned}
& \Phi=\varepsilon \Phi^{(1)}+\varepsilon^{2} \Phi^{(2)}+\cdots \\
& \eta=\varepsilon \eta^{(1)}+\varepsilon^{2} \eta^{(2)}+\cdots
\end{aligned}
$$

(2.6) と(2.7)を(2.1) (2.5)に代入し、以下のように 各オーダで整理する。

1 次オーダ

$$
\begin{aligned}
& \Delta \Phi^{(1)}=0 \\
& \Phi_{z}^{(1)}=\eta_{t}^{(1)} \text { on } \quad z=0 \\
& \Phi_{z}^{(1)}+g \eta^{(1)}=0 \quad \text { on } z=0 \\
& \Phi_{z}^{(1)}=0 \text { on } S_{B} \\
& \Phi_{v}{ }^{(1)}=0 \text { on } S_{S}
\end{aligned}
$$

2 次オーダ

$$
\Delta \Phi^{(2)}=0
$$

$\Phi_{z}^{(2)}-\eta_{t}^{(2)}=-\eta^{(1)} \Phi_{z z}{ }^{(1)}+\nabla \eta^{(1)} \cdot \nabla \Phi^{(1)} \quad$ on $\quad z=0$

$\Phi_{t}{ }^{(2)}+g \eta^{(2)}=-\eta^{(1)} \Phi_{t t}{ }^{(1)}-\frac{1}{2}\left\{\left(\nabla \Phi^{(1)}\right)^{2}+\left(\Phi_{z}{ }^{(1)}\right)^{2}\right\}$

on $z=0$

$\Phi_{z}^{(2)}=0$ on $S_{B}$

$\Phi_{\nu}{ }^{(2)}=0$ on $S_{S}$

\section{1 次オーダの解 (線形解)}

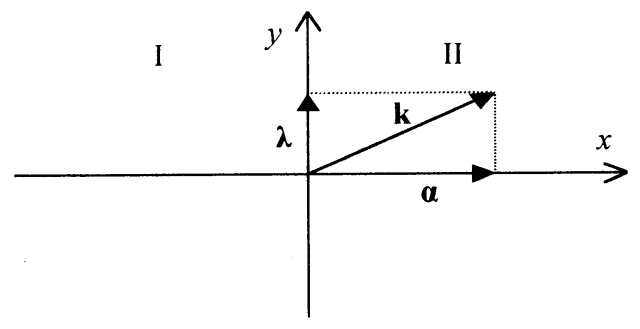

図-2＼cjkstart波数ベクトル

入射波の角周波数を $\omega$ とし、波数ベクトル（図2）を考慮すると、1 次オーダの速度ポテンシャル $\Phi^{(1)}$ は以下のように仮定できる（添字、I、II は領 域を表す）。

$$
\begin{gathered}
\Phi_{\mathrm{I}}^{(1)}=i \frac{a}{2} \frac{g}{\omega} e^{i \omega t} e^{-i \lambda y}\left\{\left(e^{-i \alpha_{\mathrm{I}} x}+C_{R} e^{i \alpha_{\mathrm{I}} x}\right) \frac{\cosh k_{\mathrm{I}}\left(z+h_{\mathrm{I}}\right)}{\cosh k_{\mathrm{I}} h_{\mathrm{I}}}\right. \\
\left.+\sum_{n=1}^{\infty} \mathrm{A}_{\mathrm{II}_{\mathrm{n}}} e^{\sigma_{\mathrm{I}_{n} x} x} \frac{\cos k_{\mathrm{I} n}(z+h)}{\cos k_{\mathrm{I} n} h}\right\}+ \text { c.c. } \\
\Phi_{\mathrm{II}}=i \frac{a}{2} \frac{g}{\omega} e^{i \omega t} e^{-i \lambda y}\left\{C_{T} e^{-i \alpha_{I I} x} \frac{\cosh k_{\mathrm{II}}\left(z+h_{\mathrm{II}}\right)}{\cosh k_{\mathrm{II}} h_{\mathrm{II}}}\right. \\
\left.+\sum_{n=1}^{\infty} \mathrm{A}_{\mathrm{II}_{\mathrm{n}}} e^{-\sigma_{\mathrm{IIn}} x} \frac{\cos k_{\mathrm{II}_{n}}\left(z+h_{\mathrm{II}}\right)}{\cos k_{\mathrm{II}_{n}} h_{\mathrm{II}}}\right\}+ \text { c.c. }
\end{gathered}
$$

ここで c.c. は共役複素数を表し、

$$
\begin{aligned}
& \alpha_{\mathrm{I}}^{2}=k_{\mathrm{I}}^{2}-\lambda^{2}, \quad \alpha_{\mathrm{II}}{ }^{2}=k_{\mathrm{II}}{ }^{2}-\lambda^{2} \\
& \sigma_{\mathrm{I} n}=\sqrt{{k_{\mathrm{I} n}}^{2}-\lambda^{2}}, \sigma_{\mathrm{II} n}=\sqrt{{k_{\mathrm{II}}}^{2}-\lambda^{2}}
\end{aligned}
$$

また、分散関係式はそれぞれの領域で、

$\omega^{2}=g k_{\mathrm{I}} \tanh k_{\mathrm{I}} h_{\mathrm{I}}=g k_{\mathrm{I} n} \tan k_{\mathrm{I} n} h_{\mathrm{I}}, n=1,2, \cdots$

$\omega^{2}=g k_{I I} \tanh k_{I I} h_{I I}=g k_{I I n} \tanh k_{I I n} h_{I I}$,

$$
n=1,2, \cdots
$$

とする。係数 $C_{R}, C_{T}, A_{\mathrm{I} n}, A_{\mathrm{II} n}$ は $z$ 軸上 $(x=0)$ の 接続条件、境界条件によって決定される。

速度ポテンシャル $\Phi$ の接続条件として、

$$
\Phi_{\mathrm{I}}^{(1)}=\Phi_{\mathrm{II}}^{\left({ }^{(1)}\right.} \text { on } z \leq-h_{\mathrm{II}}
$$

ポテンシャルの法線微分 $\Phi_{x}$ の接続条件、境界条件 として、

$$
\begin{aligned}
& \Phi_{\mathrm{L} x}^{(1)}=\Phi_{\mathrm{II} x}^{(1)} \quad \text { on } \quad z \leq-h_{\mathrm{II}} \\
& =0 \quad \text { on } \quad-h_{\mathrm{I}} \leq z \leq-h_{\mathrm{II}}
\end{aligned}
$$

となる。この (3.5)、(3.6)を使用し、図-3のように $z$ 軸上（ $x=0 ）$ に、領域 I 側の選点を $M$ 個、領域 II で $N$ 個配置する。一方、(3.1)、(3.2)の級数和の数を $M 、 N$ とする。(3.5)、(3.6)中の $z$ の值を各々の選 点について代入し、連立させることにより、係数 $C_{R}, C_{T}, A_{\mathrm{I} n}, A_{\mathrm{II} n}$ が決定する。

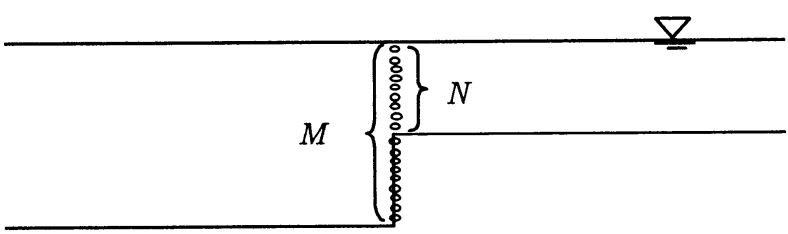

図-3 選点法

\section{2 次オーダの解（拘束波）}

今、 2 成分波を考える。 2 つの入射波の角周波数 を若干異なった值 $\omega_{1} 、 \omega_{2}$ とすると、1 次のポテン シャルは以下のようになる。

$$
\Phi^{(1)}=\phi_{1} e^{i \omega_{1} t}+\phi_{2} e^{i \omega_{2} t}+\text { c.c. }
$$

ここで便宜上、 $\phi^{(1)}$ と $\phi^{(2)}$ は一つの級数で表し、領 域 I では入射波、反射波、減衰定在波を領域 II では 透過波、減衰定在波を含んでいるものとする。また、 両領域で添字 $j$ は各々の周波数成分 $\left(j=1\right.$ の時 $\omega_{1}$ 、 $j=2$ の時 $\omega_{2}$ ) を表す。

1 次の解として、

$$
\begin{array}{r}
\phi_{j}=i \frac{a}{2} \frac{g}{\omega_{j}} e^{-i \lambda y} \sum_{n=0}^{\infty} B_{j n} e^{i \alpha_{n} x} \frac{\cosh \mu_{j}(z+h)}{\cosh \mu_{j} h} \\
(j=1,2)
\end{array}
$$

分散関係式は、

$$
\omega_{j}^{2}=g \mu_{j} \tanh \mu_{j} h \quad(j=1,2)
$$


また、各々の領域における係数は、

領域 I

$\alpha_{j_{0}}=-\alpha_{j}, \quad \alpha_{j_{1}}=\alpha_{j}, \quad \alpha_{j_{2}}=-i \sigma_{j_{1}}, \cdots$

$B_{j 0}=1, \quad B_{j_{1}}=C_{R j}, \quad B_{j_{2}}=A_{j 1}, \cdots$

$\mu_{j_{0}}=k_{j}, \quad \mu_{j_{1}}=k_{j}, \quad \mu_{j_{2}}=-i k_{j_{1}}, \cdots, \quad(j=1,2)$

領域 II

$\alpha_{j 0}=-\alpha_{j}, \quad \alpha_{j 1}=i \sigma_{j_{1}}, \quad \alpha_{j 2}=i \sigma_{j_{2}}, \ldots$

$B_{j 0}=C_{R j}, \quad B_{j 1}=A_{j_{1}}, \quad B_{j 2}=A_{j_{2}}, \cdots$

$\mu_{j 0}=k_{j}, \quad \mu_{j 1}=i k_{j_{1}}, \quad \mu_{j 2}=i k_{j_{2}}, \cdots, \quad(j=1,2)$

とする。

次に 2 次の解については、 2 成分波の場合、 (2.14)、(2.15)から様々な周波数となると考えられる が、本研究では長周期成分 $\omega_{1}-\omega_{2}$ について取り扱 うこととする。よって 2 次の拘束波は、

$$
\Phi^{(2)}=\phi^{(2)} e^{i\left(\omega_{1}-\omega_{2}\right) t}+\text { c.c. }
$$

となる。一方、2 次の拘束波が満たすべき水面条件 は(4.1)、(4.2)を(2.14)、(2.15)に代入し、 $\eta^{(1)} 、 \eta^{(2)}$ を消去すると、

$$
\begin{aligned}
& -\left(\omega_{1}-\omega_{2}\right)^{2} \phi^{(2)}+g \phi_{z}^{(2)}=i \omega_{1} \phi_{1}^{(1)} \overline{\phi_{2 z z}{ }^{(1)}} \\
& -i \omega_{2} \phi_{1 z z}{ }^{(1)} \overline{\phi_{2}{ }^{(1)}}+\frac{i}{g} \omega_{1} \omega_{2}\left(\omega_{1}-\omega_{2}\right)\left\{\phi_{1}^{(1)} \overline{\phi_{2 z}{ }^{(1)}}+\overline{\phi_{2}^{(1)}} \phi_{1 z}\right\} \\
& -i\left(\omega_{1}-\omega_{2}\right)\left\{2 \phi_{1 x}{ }^{(1)} \overline{\phi_{2 x}{ }^{(1)}}+2 \phi_{1 y}{ }^{(1)} \overline{\phi_{2 y}{ }^{(1)}}+\phi_{1 z}{ }^{(1)} \overline{\phi_{2 z}{ }^{(1)}}\right\} \\
& \text { on } z=0
\end{aligned}
$$

となる。ここで、 $\overline{\phi_{2}}$ は $\phi_{2}$ の共役複素数とする。

これらのことから、基礎方程式(2.13)、非斉次方 程式である水面条件(4.3)、底面条件(2.16)を満たす 2 次の拘束波は、

$$
\phi^{(2)}=\sum_{n=\alpha}^{\infty} \sum_{m=\alpha}^{\infty} C_{n m} e^{-i\left(\lambda_{1}-\lambda_{2}\right) y} e^{i\left(\alpha_{1 n}-\bar{\alpha}_{2 m}\right) x} \frac{\cosh v_{n m}(z+h)}{\cosh v_{n m} h}
$$

ここで、

$$
\begin{aligned}
v_{n m}= & \sqrt{\left(\lambda_{1}-\lambda_{2}\right)^{2}+\left(\alpha_{1 n}-\bar{\alpha}_{2 m}\right)^{2}} \\
C_{n m}= & \frac{i a_{1} a_{2} g^{2}}{4 \omega_{1} \omega_{2}} \frac{D_{n m} B_{1 n} \overline{B_{2 m}}}{g v_{n m} \tanh v_{n m} h-\left(\omega_{1}-\omega_{2}\right)^{2}} \\
D_{n m}= & \omega_{1}\left(\mu_{2 m}\right)^{2}-\omega_{2}\left(\mu_{1 n}\right)^{2}+\frac{\omega_{1} \omega_{2}\left(\omega_{1}-\omega_{2}\right)\left(\omega_{1}^{2}+\omega_{2}^{2}\right)}{g^{2}} \\
& +\left(\omega_{2}-\omega_{1}\right)\left(2 \alpha_{1 n} \bar{\alpha}_{2 m}+2 \lambda_{1} \lambda_{2}+\frac{\omega_{1}^{2} \omega_{2}^{2}}{g^{2}}\right)
\end{aligned}
$$

となる。

\section{2次オーダの解（自由波）}

これまで、(2.13)〜(2.16)を満たす拘束波を導出し たが、拘束波はステップ前面の境界条件(2.17) と接 続条件を満たしていない。それを補償するものとし
て自由波が発生し、拘束波と自由波ですべての境界 条件を満足するものである。自由波の基礎方程式、 境界条件を以下に示寸。

$$
\begin{aligned}
& \Delta \Phi_{F}{ }^{(2)}=0 \\
& \Phi_{F i t}{ }^{(2)}+g \Phi_{F}{ }^{(2)}=0 \text { on } \quad z=0 \\
& \Phi_{F z}{ }^{(2)}=0 \text { on } S_{B} \\
& \Phi_{F v}{ }^{(2)}=0 \text { on } S_{S}
\end{aligned}
$$

ここで水面条件(5.2)は斉次方程式である。

角周波数が $\omega_{1}-\omega_{2}$ で、(5.1) (5.3)これらの条件 を満たす自由波は、

領域 I で、

$$
\begin{aligned}
\Phi_{\mathrm{F} \mathrm{I}}= & i \frac{a_{1} a_{2} g}{\left(\omega_{1}-\omega_{2}\right)} e^{-i \lambda_{F} y}\left\{E_{0} e^{i \alpha_{F 1} x} \frac{\cosh k_{\mathrm{F} \mathrm{I}}\left(z+h_{\mathrm{I}}\right)}{\cosh k_{\mathrm{F}} h_{\mathrm{I}}}\right. \\
& \left.+\sum_{n=1}^{\infty} E_{n} e^{\sigma_{F \mathrm{In}} x} \frac{\cos \xi_{\mathrm{In}}\left(z+h_{\mathrm{I}}\right)}{\cos \xi_{\mathrm{In}} h_{\mathrm{I}}}\right\} e^{i\left(\omega_{1}-\omega_{2}\right) t}
\end{aligned}
$$

領域 II で、

$$
\begin{aligned}
\Phi_{\mathrm{F} \mathrm{II}}= & i \frac{a_{1} a_{2} g}{\omega_{1}-\omega_{2}} e^{i \lambda_{F} y}\left\{F_{0} e^{-i \alpha_{F \amalg} x} \frac{\cosh k_{F \mathrm{II}}\left(z+h_{\mathrm{II}}\right)}{\cosh k_{F \mathrm{I}} h_{\mathrm{II}}}\right. \\
& \left.+\sum_{n=1}^{\infty} F_{n} e^{-\sigma_{F \cdot \mathrm{IIn}} x} \frac{\cos \xi_{\mathrm{IIn}}\left(z+h_{\mathrm{II}}\right)}{\cos \xi_{\mathrm{In}} h_{\mathrm{II}}}\right\} e^{i\left(\omega_{1}-\omega_{2}\right) t}
\end{aligned}
$$

となる。

ここで分散関係式は、

$\left(\omega_{1}-\omega_{2}\right)^{2}=g k_{\mathrm{F}} \tanh k_{\mathrm{F} \mathrm{I}} h_{\mathrm{I}}=-g \xi_{\mathrm{In}} \tan \xi_{\mathrm{In}} h_{\mathrm{I}}$

$\left(\omega_{1}-\omega_{2}\right)^{2}=g k_{\mathrm{F} \mathrm{II}} \tanh k_{\mathrm{FI}} h_{\mathrm{II}}=-g \xi_{\mathrm{In}} \tan \xi_{\mathrm{In}} h_{\mathrm{II}}$

(5.5)、(5.6)中の係数 $E_{n} 、 F_{n}$ は、1 1 次の解の係数同 様、以下の接続条件とステップ前面の境界条件より 決まる。

$$
\begin{aligned}
\Phi_{\mathrm{I}}^{(2)}+\Phi_{F \cdot \mathrm{I}}{ }^{(2)} & =\Phi_{\mathrm{II}}{ }^{(2)}+\Phi_{F+\mathrm{II}}^{(2)} \quad \text { on } \quad z \leq-h_{\mathrm{II}} \\
\Phi_{\mathrm{I} x}{ }^{(2)}+\Phi_{l \cdot \mathrm{Tx}}{ }^{(2)} & =\Phi_{\mathrm{II} x}{ }^{(2)}+\Phi_{F \mathrm{IIx}}{ }^{(2)} \quad \text { on } \quad z \leq-h_{\mathrm{II}} \\
& =0 \quad \text { on }-h_{\mathrm{I}} \leq z \leq-h_{\mathrm{II}}
\end{aligned}
$$

\section{6. 進行性長周期自由波の発生限界}

啲束波(4.4)U水平方向U関数形は、

$$
e^{i\left(\alpha_{1 n}-\bar{\alpha}_{2 m}\right) x} e^{-i\left(\lambda_{1}-\lambda_{2}\right) y}
$$

となり、ステップ先端上 $(x=0)$ での $y$ 方向の波数 は $\lambda_{1}-\lambda_{2}$ である。自由波はステップ先端上を擾乱 源としていることから、自由波の $y$ 方向の波数は拘 束波と一致しなければならない。

$$
\lambda_{F I}=\lambda_{F I I}=\lambda_{1}-\lambda_{2}
$$

一方、自由波の波数は、(5.7)、(5.8)の分散関係 式から得られる。従って、 $x$ 方向の波数 $\alpha_{F}$ は以下 のような関係から導かれる。 


$$
\begin{aligned}
& \mathbf{k}_{\mathrm{I}}=\left(\alpha_{F \mathrm{1}}, \lambda_{1}-\lambda_{2}\right) \\
& \mathbf{k}_{\mathrm{II}}=\left(\alpha_{F \mathrm{II}}, \lambda_{1}-\lambda_{2}\right)
\end{aligned}
$$

もしくは、

$$
\begin{aligned}
& \alpha_{F \mathrm{I}}^{2}=k_{F \mathrm{I}}{ }^{2}-\left(\lambda_{1}-\lambda_{2}\right)^{2} \\
& \alpha_{F+1}^{2}=k_{F \mathrm{TI}}^{2}-\left(\lambda_{1}-\lambda_{2}\right)^{2}
\end{aligned}
$$

(6.3)、(6.4)の右辺が負の場合、自由波は $x$ 方向に減 衰し、進行性の自由波とならない。これは 2 成分の 入射波の波数べクトルを $\mathbf{k}_{1} 、 \mathbf{k}_{2}$ とし、拘束波の波 数べクトルは $\mathbf{k}_{1}-\mathbf{k}_{2}$ とすると、図-4と図-5より、

$$
\left|\mathbf{k}_{1}-\mathbf{k}_{2}\right| \geq k_{1}-k_{2} \geq k_{F}
$$

となる。入射周波数を $\omega_{1} 、 \omega_{2}$ と一定とすると（ $k_{1}$ 、 $k_{2}$ を一定）、 $\lambda_{1}-\lambda_{2}$ の最大值は $\left|\mathbf{k}_{1}-\mathbf{k}_{2}\right|$ である。 よって、 $\lambda_{1}-\lambda_{2}$ が最大の場合、次式が得られる。

$$
\lambda_{1}-\lambda_{2} \geq k_{F}
$$

これは $\lambda_{1}-\lambda_{2}>k_{F}$ の時、進行性の自由波が発生せ ず、 $\lambda_{1}-\lambda_{2}=k_{F}$ で $y$ 軸に平行に進行する波となる ことを示している。

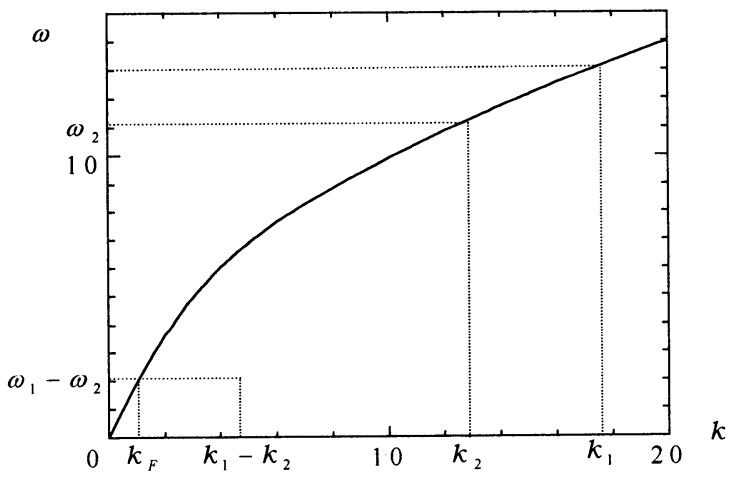

図-4 分散関係

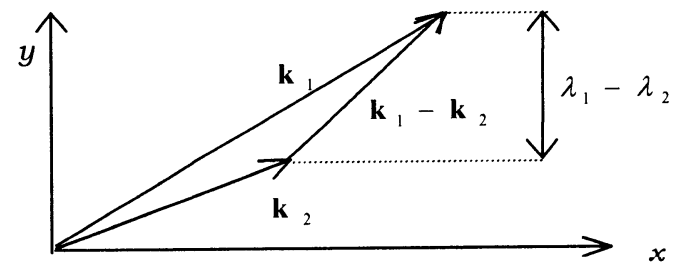

図-5 1 次波と拘束波の波数ベクトルの関係

領域 I、II では、常に

$$
h_{\mathrm{I}}>h_{\mathrm{II}}
$$

であるから、波数に関しては、(3.3)、(3.4)より

$$
k_{\mathrm{I}}<k_{\mathrm{II}}
$$

となる。従って、進行性の自由波が発生する割合は 領域 I よりも領域 II が大きい。これは特定の入射角 で入射した場合、領域Iだけに進行性の自由波が発 生するということを示している。この場合、領域 II の奥に海岸などがあれば、発生した自由波がステッ プ先端に戻るが、 $y$ 方向の波数は同じであるから再 び反射し進行性の自由波の振幅が増幅することを示 唆する。

\section{7. 結果と考察}

自由波の振幅は接続境界上の拘束波の差の大きさ に依存し、拘束波は 2 次の水面条件 (4.3) から 1 次 波によって決まる。それ故、自由波の振幅を議論す る前に、1 次のポテンシャルについて詳しくみてい くこととする。図-6(a)，(b) は接続境界 $(x=0)$ の速 度ポテンシャルとその法線微分を水深に沿って選点 以外の点も計算したものである。図-6(a) から 1 次 のポテンシャルは領域 I 、IIで実部、虚部ともに一 致していることが分かる。次に図-6(b) は、 $x=0$ で 速度ポテンシャルの法線微分を示したものである。 これは選点ではそれぞれ一致しているが、選点以外 では一致せず振動していることが分かる。この現象 はGibbsの現象で、接続条件、ステップ前面の境界 条件を満たしていないことが分かる。級数和の数を 増やしても常にGibbsの現象が起こるので、それに 依存する自由波の振幅について議論をしないことと する。

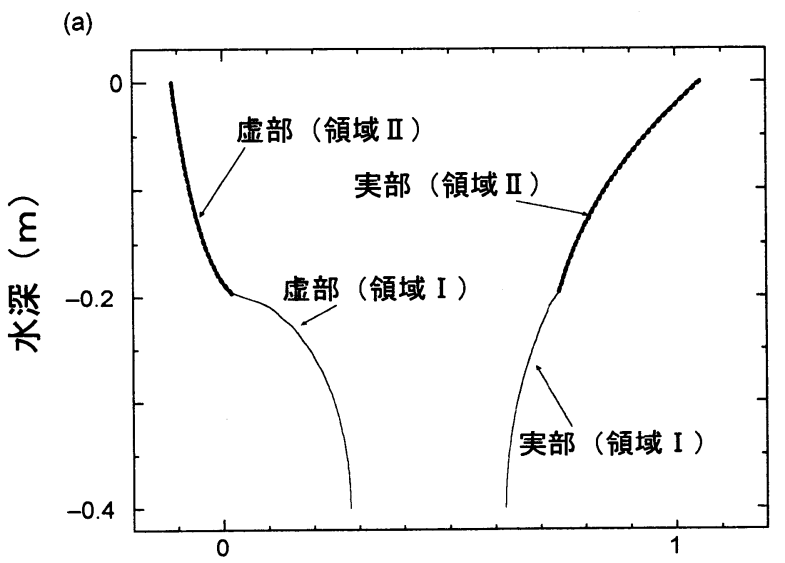

(b)

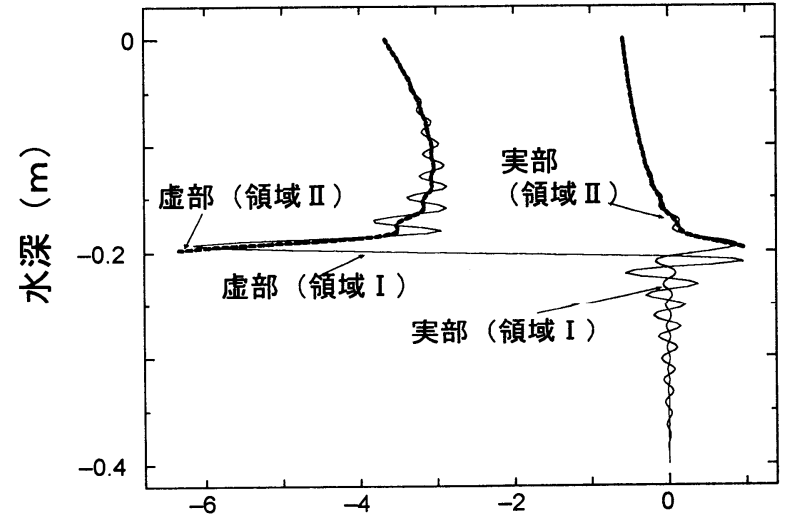

図-6 接続境界上 $(x=0)$ の 1 次波 $h_{I}=0.4 \mathrm{~m} 、 h_{I I}=0.2 \mathrm{~m} 、 \omega=5 \mathrm{~s}^{-1}$

$$
M=40 、 N=20
$$

(a) 速度ポテンシャル

(b) 速度ポテンシャルの法線微分

一方、自由波の波長と波向は自由波の分散関係と 拘束波の波向によって決まり、Gibbsの現象の影響 を受けない。図-7〜9は、特に進行性自由波の発生 

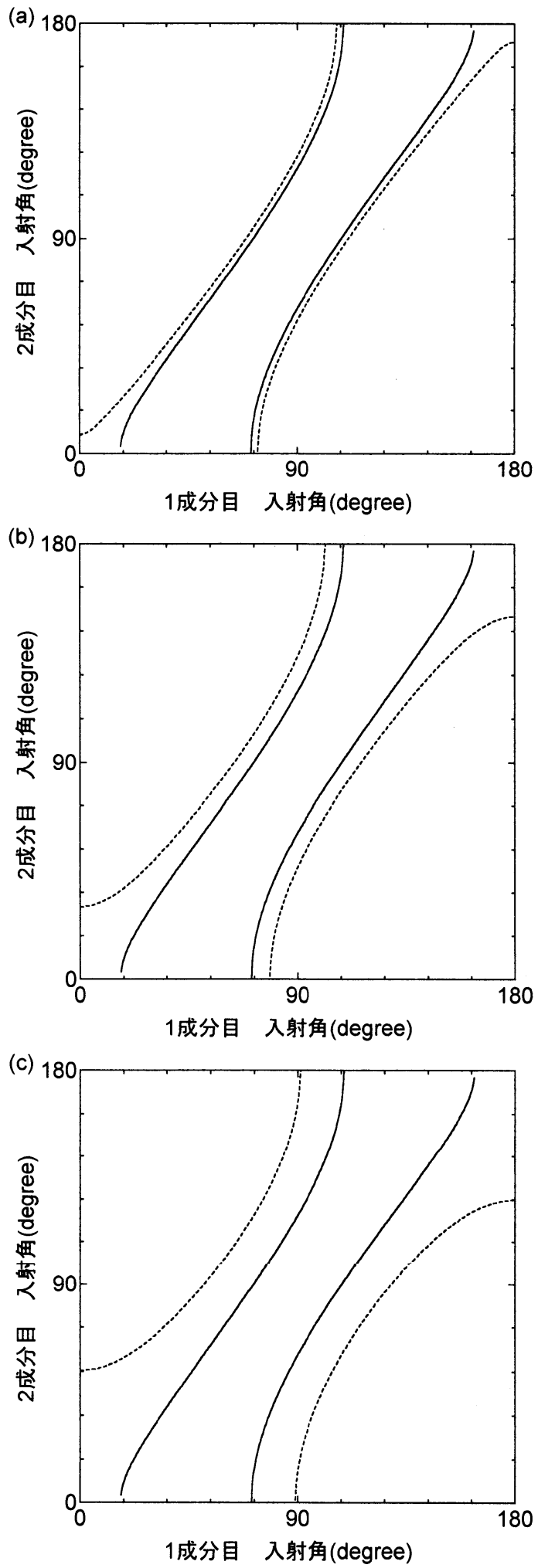

図-7 入射角に対する進行性自由波の発生限界

$$
\begin{gathered}
\omega_{1}-\omega_{2}=1.0 \mathrm{~s}^{-1} 、 h_{l}=0.4 \mathrm{~m} 、 \\
\omega_{1}=3.0 \mathrm{~s}^{-1} 、 \omega_{2}=2.0 \mathrm{~s}^{-1}
\end{gathered}
$$
(a) $h_{l l}=0.3 \mathrm{~m}$
(b) $h_{l l}=0.2 \mathrm{~m}$
(c) $h_{l l}=0.1 \mathrm{~m}$
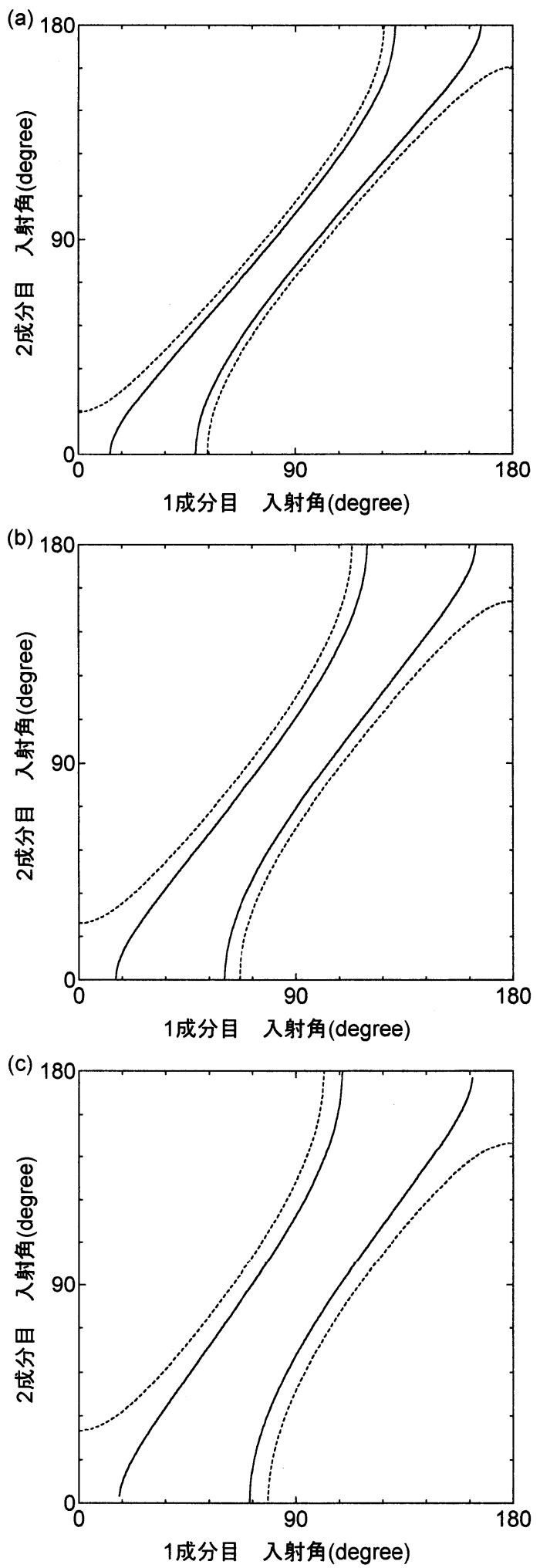

図-8 入射角に対する進行性自由波の発生限界

$$
\omega_{1}=3.0 \mathrm{~s}^{-1} 、 h_{l}=0.4 \mathrm{~m} 、 h_{I I}=0.2 \mathrm{~m}
$$
(a) $\omega_{1}-\omega_{2}=0.5 \mathrm{~s}^{-1}$
(b) $\omega_{1}-\omega_{2}=0.75 \mathrm{~s}^{-1}$
(c) $\omega_{1}-\omega_{2}=1.0 \mathrm{~s}^{-1}$ 

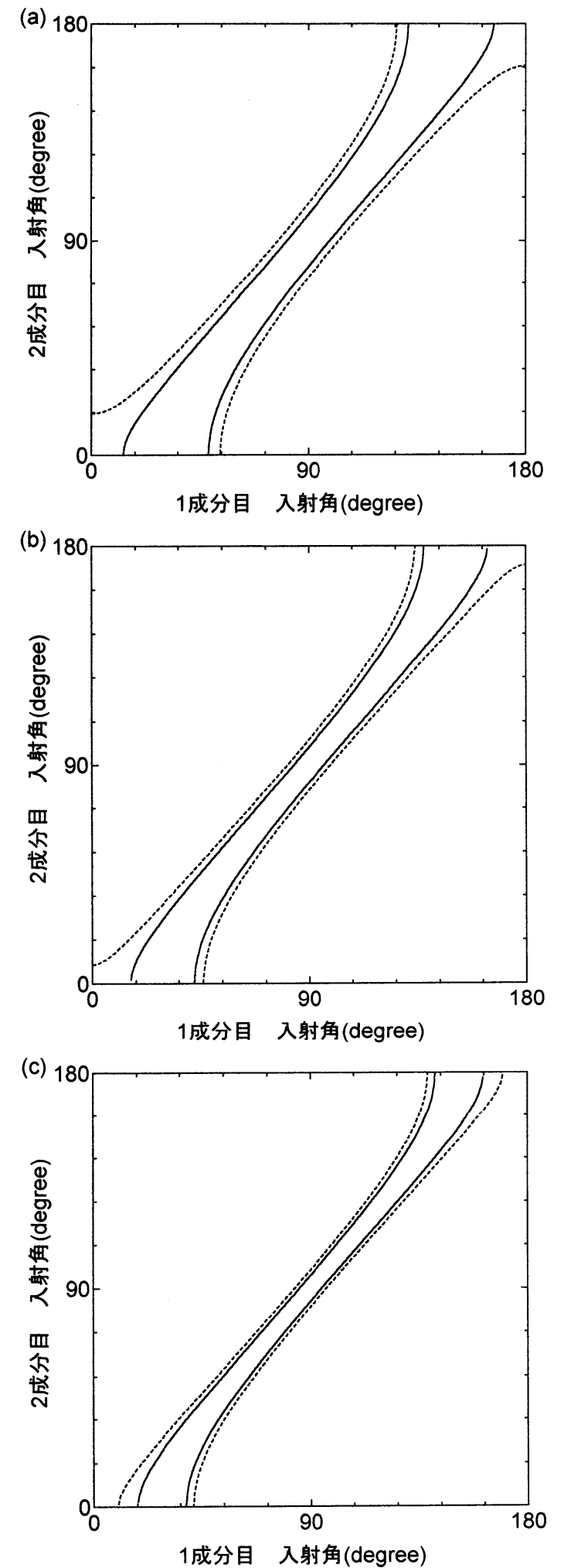

図-9 入射角に対する進行性自由波の発生限界 $\omega_{1}-\omega_{2}=0.5 \mathrm{~s}^{-1}$
$h_{I}=0.4 \mathrm{~m} 、 h_{I I}=0.2 \mathrm{~m}$
(a) $\omega_{1}=3.0 \mathrm{~s}^{-1}$
(b) $\omega_{1}=4.0 \mathrm{~s}^{-1}$
(c) $\omega_{1}=5.0 \mathrm{~s}^{-1}$

範囲について計算したものである。横軸は 1 成分目 $\left(\omega_{1}\right)$ の入射角を示し、縦軸は 2 成分目 $\left(\omega_{2}\right)$ の入 射角である。2つの実線の間は領域 I で進行性自由 波となる範囲で、2つの破線の間は領域 II のそれで ある。図-7は1,2成分の角周波数、領域 I の水梁は 固定し、領域 II の水深を変化させたものである。こ の図から、領域 II の水深が浅くなると、領域 II で進 行性自由波になりやすいことを示している。図-8は 1 成分目の角周波数を固定し、発生する自由波の角 周波数を変化させたものである。この図から、領域 I 、II ともに自由波の角周波数が大きくなるにした がって、進行性自由波の発生範囲も大きくなってい ることが分かる。図-9は発生する自由波の角周波数 を固定し、1 成分目の角周波数を変化させたもので ある。この図から、同じ角周波数の自由波が発生す るのならば、入射波の周波数が小さいほど進行性の 自由波の発生範囲が大きいことが分かる。また、こ れらのすべての図で、進行性自由波が領域 I で発生 せず、領域 II で発生している範囲が存在することが 分かる。

\section{8. まとめ}

ステップ上を 2 成分波が通過するときに発生する 長周期自由波について、摂動法を用いて解析した。 1 次オーダの解は選点法で係数を求めているため Gibbsの現象が現れる。このため選点以外で接続条 件、ステップ前面の境界条件を 1 次のポテンシャル の法線微分が満たさないことから、発生する自由波 の振幅については議論しなかった。

2 成分波がそれぞれ角度を持って入射する場合、 発生する自由波は進行性自由波、または減衰性自由 波となり、進行性自由波が領域 I で発生せず、領域 II で発生している範囲が存在することから、このよ うな条件では、領域 II の奥に反射物が存在すれば自 由波の振幅が増幅する可能性があるといえる。

今後の課題としては、Gibbsの現象を回避する解 析を考え、自由波の振幅について詳細に検討寸る必 要がある。

\section{参考文献}

1) 合田良実, 岡崎健一：矩形ステップ上の非線形波 浪干涉と砕波限界, 海岸工学論文集, 第 45 巻, pp. 46-50, 1998.

2) Agnon, Y. and C.C.Mei: Trapping and resonance of long shelf waves due to groups of short waves, J. Fluid Mech., Vol.195, pp201-221, 1988.

3) Massel,S.R.: Harmonic generation by wave propagation over a submerged step, Coastal Engg., Vol.7, pp357-380, 1983. 